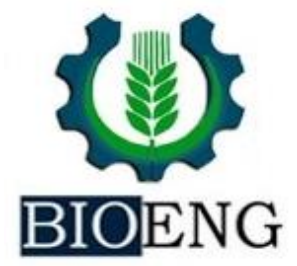

\title{
ESTOQUES DE CARBONO E RETENÇÃO HÍDRICA EM BIOMASSA DE GRAMÍNEAS NO AGRESTE DA PARAÍBA
}

\section{P. L. F. da Silva ${ }^{1 *}$, F. P. de Oliveira ${ }^{1}$,W. E. Pereira ${ }^{2}$, J. O. de M.}

Borba $^{1}$, D. D. Tavares ${ }^{3}$, T. E. D. Santos ${ }^{4}$, A. F. Martins ${ }^{1}$

${ }^{1}$ UFPB - Universidade Federal da Paraíba, Centro de Ciências Agrárias, Departamento de Solos e Engenharia Rural, Areia, PB, Brasil.

${ }^{2}$ UFPB - Universidade Federal da Paraíba, Centro de Ciências Agrárias, Departamento de Ciências Fundamentais e Sociais, Areia, PB, Brasil.

${ }^{3}$ UFRPE - Universidade Federal Rural de Pernambuco, Departamento de Agronomia, Recife, PE, Brasil.

${ }^{4}$ UFLA - Universidade Federal de Lavras, Departamento de Ciência do Solo, Lavras, MG, Brasil.

Article history: Received 21 May 2019; Received in revised form 03 June 2019; Accepted 05 June 2019 ; Available online 24 June 2019.

\section{RESUMO}

O sistema de manejo, quando adotado de forma incorreta pode ocasionar à degradação física, química e biológica do solo, principalmente na ausência de cobertura vegetal. A escolha da gramínea é parte fundamental nos sitemas de produção, principalmente quanto a produção de matéria seca e a deposição de carbono ao solo, favorecendo a recuperação de ambientes degradados. Sendo assim, objetivou-se com este trabalho avaliar o estoque de carbono e a retenção hídrica em biomassa de gramíneas cultivadas no agreste da Paraíba. O experimento foi instalado em área experimental do Centro de Ciências Agrárias da Universidade Federal da Paraíba, Areia (PB) (6 58'12''S; 35 41'15' W). O delineamento foi de blocos casualisados composto pelos seguintes tratamentos T1 - Brachiaria decumbens Stapf., T2 Brachiaria brizantha, T3 - Brachiaria humidicola (Rendle) Schweick vr., T4 - Brachiaria brizantha cv. MG5 - Vitória e T5 - Sem cobertura vegetal. As variáveis analisadas foram: carbono orgânico total, estoque de carbono, produção de matéria seca e reteção hídrica na matéria seca. De acordo com os resultados, a Brachiaria brizantha foi superior na produção de matéria seca e na capacidade de retenção hídrica. O carbono orgânico total e o estoque de carbono não variaram entre os tratamentos avaliados.

Palavras-chave: Brachiaria brizantha, cobertura do solo, retenção hídrica, matéria orgânica.

\section{CARBON STOCKS AND HYDRICAL RETENTION IN GRASS BIOMASS IN THE PARAÍBA AGRESTE MESOREGION}

\begin{abstract}
The management system, when improperly adopted, can lead to physical, chemical and biological soil degradation, especially in the absence of vegetation cover. The selection of grasses is a fundamental part of the production systems, mainly regarding the dry matter production and the deposition of carbon to the soil, favoring the recovery of degraded environments. Thus, the objective of this work was to evaluate the carbon stock and water retention in biomass of grasses grown in the Paraiba Agreste. The experiment was installed in an experimental area of the Center of Agricultural Sciences of the Federal University of
\end{abstract}

*pedroluanferreira@gmail.com 
Paraiba, Areia (PB) $\left(6^{\circ} 58^{\prime} 12 " \mathrm{~S} ; 35^{\circ} 41^{\prime} 15^{\prime \prime} \mathrm{W}\right)$. The design was of randomized blocks composed of the following treatments T1 - Brachiaria decumbens Stapf., T2 - Brachiaria brizantha, T3 - Brachiaria humidicola (Rendle) Schweick vr., T4 - Brachiaria brizantha cv. MG5 - Vitória e T5 - Without vegetal cover. The variables analyzed were: total organic carbon, carbon stock, dry mass production and water retention in the dry mass. According to the results, Brachiaria brizantha was superior in dry mass production and water retention capacity. Total organic carbon and carbon stock did not vary between treatments.

Keywords: Brachiaria brizantha, soil cover, water retention, organic matter.

\section{INTRODUÇÃO}

O carbono orgânico é um dos atributos utilizados como indicador de qualidade do solo e destaca-se diante dos demais atributos, por ser um dos mais sensíveis as mudanças de manejo do solo (SOARES et al., 2018).Estima-se que aproximadamente $58 \%$ da matéria orgânica do solo é composta por carbono e seus benefícios para o ambiente são inúmeros, destacando-se as melhorias nas propriedades físicas, químicas e biológicas do solo, além de fornecer informações importantes relacionadas a qualidade do solo e mensurar o impacto dos sistemas de manejo sobre a sustentabilidade da produção agrícola (MIELNICZUK, 2008).

Entre os indicadores de qualidade do solo relacionados as variações e formas de carbono no solo, destaca-se o estoque de carbono, em função de sua grande importância na predição da sustentabilidade dos sistemas de produção, pois, a depender do sistema de manejo adotado, os seus teores podem permanecer estáveis, aumentar ou diminuir em relação as áreas onde não há interferência de ordem antrópica (NANZER et al., 2019). Contudo, a degradação do solo promovida por sistemas de produção mal dimensionados tem ocasionado umaredução significativa no carbono do solo e elevado as emissão de gases para a atmosfera (ROSA et al., 2014), demandando assim, sistemas de produção que promovam melhorias na fixação de carbono no solo sem interfrir na produção agropecuária.
As gramíneas, por serem facilmente adaptadas aos diferentes sistemas de produção agropecuária, podem ser utilizadas na fixação e manutenção de carbono no solo em função da grande produção de biomassa, principalmente em ambientes com manejo cultural controlado. A sua palhada além de apresentar elevada relação $\mathrm{C} / \mathrm{N}$, promove melhorias na retenção de água no solo, redução na amplitude térmica e no deslocamento do solo ocasionado pelo escoamento superficial (SILVA et al., 2018), alémde melhorias nos índices de produtividade e disponibilidade de água (BRAGA et al., 2017). Portando a escolha da gramínea para produção de cobertura morta é de grande importância para os sistemas de produção e deve ser feita levando-se em consideração alguns parâmetros, dentre eles aprodução de matéria seca e capacidade de retenção hídrica.

A capacidade de retenção hídrica vem sendo utilizada como um parâmetro intrinsceco na escolha do tipo de material a ser utilizado como cobertura morta (COSTA et al., 2007). Contudo, verifica-se na literatura uma lacuna quando se fala em dados sobre retenção hídricae produção de massa seca em gramíneas para sistemas de produção agrícola na região Nordeste.

Sendo assim, objetivou-se com este trabalho avaliar o estoque de carbono e a retenção hídrica na matéria seca de gramíneas cultivadas no Agreste da Paraíba. 


\section{MATERIAL E MÉTODOS}

O experimento foi instalado no ano de 2006 em área experimental do Centro de Ciências Agrárias da Universidade Federal da Paraíba, em Areia (PB). O município está inserido na microrregião do Brejo e mesorregião do Agreste da Paraíba (6'58'12''S; 3541'15' W). Conforme a classificação de Köppen, o clima que predomina no município é do tipo As' tropical, quente e úmido, com chuvas no período de outono e inverno e precipitação média anual de $1.400 \mathrm{~mm}$ (ALMEIDA et al., 2014). Apresenta altitude média de 620 $\mathrm{m}$.

A temperatura média anual é de 24,5 ${ }^{\circ} \mathrm{C}$ e a umidade relativa do ar ao entorno de UR - 80\%. Quanto ao período chuvoso, $62 \%$ da precipitação anual distribui-se entre os meses de abril e julho (OLIVEIRA et al., 2009; LIMA et al., 2014).

O solo da área experimental é classificado como Latossolo Amarelo distrófico (EMBRAPA, 2013) e de textura argilo-arenosa.A caracterização química e de fertilidade do solo da área experimental demonstrou os seguintes valores para os atributos: $\mathrm{pH}=5,3\left(\mathrm{H}_{2} \mathrm{O} \quad 1: 2,5\right) ; \mathrm{Ca}^{2+}=$ $1,89 \mathrm{cmol}_{\mathrm{c}} \mathrm{dm}^{-3}, \mathrm{Mg}^{2+}=1,43 \mathrm{cmol}_{\mathrm{c}} \mathrm{dm}^{-3}$, $\mathrm{Al}^{3+}=0,30 \quad \mathrm{cmol}_{\mathrm{c}} \mathrm{dm}^{-3}, \mathrm{H}+\mathrm{Al}^{3+}=8,33$ $\mathrm{cmol}_{\mathrm{c}} \mathrm{dm}^{-3}, \mathrm{SB}=3,46 \mathrm{cmol}_{\mathrm{c}} \mathrm{dm}^{-3}, \mathrm{CTC}=$ $11,79 \mathrm{cmol}_{\mathrm{c}} \mathrm{dm}^{-3}, \mathrm{Na}^{+}=0,06 \mathrm{cmol}_{\mathrm{c}} \mathrm{dm}^{-3}$; MOS $=49,52 \mathrm{~g} \mathrm{~kg}^{-1} ; \mathrm{P}=1,82 \mathrm{mg} \mathrm{dm}^{-3} \mathrm{e}$ $\mathrm{K}^{+}=28,37 \mathrm{mg} \mathrm{dm}^{-3}$. A caracterização física do solo da área experimental encontra-se na (Tabela 1).

Tabela 1. Caracterização física de solo da área experimental, para a camada avaliada de 0 $0,10 \mathrm{~m}$.

\begin{tabular}{|c|c|c|c|c|c|c|c|c|c|}
\hline \multicolumn{2}{|c|}{ Areia } & \multirow{2}{*}{ Silte } & \multirow{2}{*}{ Argila } & \multirow{2}{*}{ ADA } & \multirow{2}{*}{ GF } & \multirow{2}{*}{ S/A } & \multirow{2}{*}{ Ds } & \multirow{2}{*}{$\mathrm{Dp}$} & \multirow{2}{*}{ PT } \\
\hline Grossa & Fina & & & & & & & & \\
\hline \multirow{2}{*}{\multicolumn{3}{|c|}{ 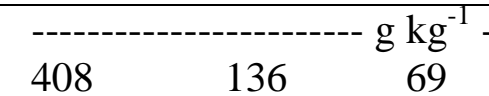 }} & - & - & $-\cdots$ & & \multicolumn{2}{|c|}{$--\mathrm{g} \mathrm{cm}^{-3}---$} & $\mathrm{m}^{3} \mathrm{~m}^{-3}$ \\
\hline & & & 357 & 14,15 & 958 & 0,194 & 1,18 & 2,58 & 0,46 \\
\hline
\end{tabular}

\section{Delineamento experimental e variáveis analisadas}

O delineamento experimental adotado foi em blocos casualizados (DBC), com cinco tratamentos e quatro repetições (5 x 4). Os tratamentos avaliados foram os seguintes: T1 - Brachiaria decumbens Stapf., T2 - Brachiaria brizantha, T3 Brachiaria humidicola (Rendle) Schweick vr. T4 - Brachiaria brizantha cv. MG5 Vitória e T5 - Sem cobertura vegetal mantida descoberta desde o ano de 2018, mas anteriormente apresentava-se coberta com Brachiaria ruziziensis. As parcelas experimentais (total de 20), tinham área útil de $50 \mathrm{~m}^{2}(10 \times 5 \mathrm{~m})$, distanciandoum metro $(1 \mathrm{~m})$ entre si e dois metros $(2 \mathrm{~m})$ entre blocos.

\section{Determinação do carbono orgânico total (COT)}

Amostras de solo com estrutura deformada foram coletadas com auxílio de pá de corte, secas ao ar e passadas em peneira com malha de $2 \mathrm{~mm}$. Posteriormente foram encaminhadas ao Laboratório de Química e Fertilidade do solo do Centro de Ciências Agrárias da Universidade Federal da Paraíba para determinação das variáveis químicas.

O carbono orgânico total (COT) foi determinado em solo via úmida pela oxidação com o dicromato de potássio $\mathrm{K}_{2} \mathrm{Cr}_{2} 0_{7} \quad\left(0,0667\right.$ mol $\left.\mathrm{L}^{-1}\right)$, conforme recomendado por Teixeira et al. (2017). O estoque de carbono (ESTC) foi calculado conforme metodologia proposta por Veldkamp (1994) e por Fernandes e Fernandes (2008). A expressão utilizada para calcular o ESTC, encontra-se abaixo: 
$\operatorname{ESTC}\left(\mathrm{Mg} \mathrm{ha}^{-1}\right)=(\mathrm{CO} \times$ Ds x e $) / 10(1)$

Em que: ESTC - é o estoque de carbono no solo; $\mathrm{CO}$ - teor de carbono orgânico encontrado na amostra de solo ( $\mathrm{g}$ $\left.\mathrm{kg}^{-1}\right)$, Ds - densidade do solo $\left(\mathrm{g} \mathrm{cm}^{-3}\right), \mathrm{e}-$ espessura da camada de solo avaliada $(\mathrm{cm})$.

\section{Determinação da retenção hídrica e da} produção de matéria seca em gramíneas

Utilizou-se um gabarito de madeira nas dimensões de 0,30 x $0,21 \mathrm{~m}\left(0,063 \mathrm{~m}^{2}\right)$ para a coleta da matéria seca das gramíneas no mês de novembro de 2018. As amostras foram coletadas de forma aleatória em três pontos distintos das 16 parcelas experimentais, totalizando 48 pontosamostrados. Todo o material coletado dentro do gabarito foi acondicionado em sacos e encaminhado ao Laboratório de AnállisesFísicas deSolo para a realização de análises. As variáveis determinadas foram: produção de matéria seca $\left(\mathrm{kg} \mathrm{ha}^{-1}\right)$ e capacidade de retenção hídrica na matéria seca (CRH - $\left.\mathrm{g} \mathrm{g}^{-1}\right)$.

A avaliação da capacidade de retenção hídrica na matéria seca das gramíneas foi realizada seguindo a metodologia proposta por Blow (1955) e Martins et al. (2018). Os referidos autores avaliaram a capacidade de retenção hídrica em serrapilheira de espécies florestais, submergindo as subamostras do material coletado em recipiente com água destilada por um intervalo de 90 minutos; após esse período as amostras foram colocadas em peneiras com malha superior a $2(\mathrm{~mm})$,

\section{RESULTADOS E DISCUSSÃO}

\section{Produção de matéra seca e Retenção hídrica na matéria seca}

Na Tabela 2, encontra-se apresentado o resumo da análise de variância (ANOVA) para os atributos: produção de matéria seca (PMS), retenção hídrica na com uma inclinação de $30^{\circ}$, por 30 minutos, de forma a remover o excesso de água retida.

As amostras foram pesadas em balança analítica para a obtenção da massa úmida e, posteriormente acondicionadas em sacos de papel para secagem em estufa por um período de 72 horas a uma temperatura constante de $70{ }^{\circ} \mathrm{C}$. O mesmo procedimento foi adotado para avaliar a capacidade de retenção hídrica $(\mathrm{CRH})$ nas gramíneas, excetuando-se o intervalo de secagem, que foi reduzido a 48 horas, em função da facilidade de combustão do material avaliado.

A equação utilizada para obtenção dos valores médios de retenção hídrica segue abaixo. Ela foi ajustada de forma a obter os valores médios em $\mathrm{g} \mathrm{g}^{-1}$ e não em (\%), como originalmente proposto por Blow (1955) e Martins et al. (2018).

$$
\mathrm{CRH}=\mathrm{MGU}-\mathrm{MGS} / \mathrm{MGS} * 1000(2)
$$

Em que: CRH - é a capacidade de retenção hídrica, MGU - massa da gramínea úmida $(\mathrm{kg})$ e MGS - massa da gramínea seca $(\mathrm{kg})$.

\section{Análise estatística dos dados}

Realizou-se a análise de variância e as médias foram comparadas pelo teste de Tukey ao nível de $5 \%$ de probabilidade $(p<0,05)$, utilizando o software estatístico $\mathrm{R}$ (R DEVELOPMENT, 2013). As médias também foram agrupadas através da análise dos componentes principais (ACP).

matéria seca $(\mathrm{CRH})$, carbono orgânico total (COT) e estoque de carbono (ESTC), ao nível de $(p<0,05)$. 
Tabela 2. Resumo da análise de variância para os atributos produção de matéria seca (PMS), retenção hídrica na matéria seca $(\mathrm{CRH})$, carbono orgânico total (COT) e estoque de carbono (ESTC).

\begin{tabular}{cccccc}
\hline \multirow{2}{*}{ FV } & \multirow{2}{*}{ GL } & \multicolumn{5}{c}{ QM } \\
\cline { 3 - 6 } & & PMS & CRH & COT & ESTC \\
\hline Blocos & 3 & 592 & 0,27 & 66,31 & 159,15 \\
Diferentes coberturas do solo & 4 & $338^{* *}$ & $5,19 * *$ & $118,76^{\mathrm{ns}}$ & $250,26^{\mathrm{ns}}$ \\
Resíduo & 12 & 391 & 0,16 & 52,28 & 139,19 \\
\hline Total & 19 & \multicolumn{5}{c}{} \\
\hline
\end{tabular}

Na Figura 1, observa-se a produção de matéria seca das gramíneas utilizadas como cobertura de Latossolo no Agreste da Paraíba. Houve variação significativa a $(p<0,05)$ para todas as gramíneas avaliadas, destacando-se a Brachiaria brizantha por apresentar uma produção média de $3383 \mathrm{~kg} \mathrm{ha}^{-1}$. Seguido dos tratamentos Brachiaria humidicola e Brachiaria decumbens. A menor produção de matéria seca foi verificada no Brachiaria brizantha MG5 cv Vitória. Fontes et al. (2014) trabalhando com acúmulo de matéria seca em cultivares de Brachiaria brizantha encontratam uma produção média de $5202,4 \mathrm{~kg} \mathrm{ha}^{-1}$ para o cultivar marandú, porém sob condições controladas de manejo e adubação do solo.

$\mathrm{O}$ valor foi bem superior ao verificado nesse estudo, contudo deve-se salientar que a Brachiaria brizantha atingiu essa produção em condições de sequeiro, sendo a última adubação foi realizada no ano de 2009 por Vasconcelos et al. (2010), em trabalhos sobre o efeito da adubação sobre o índice de estabilidade de agregados do solo.

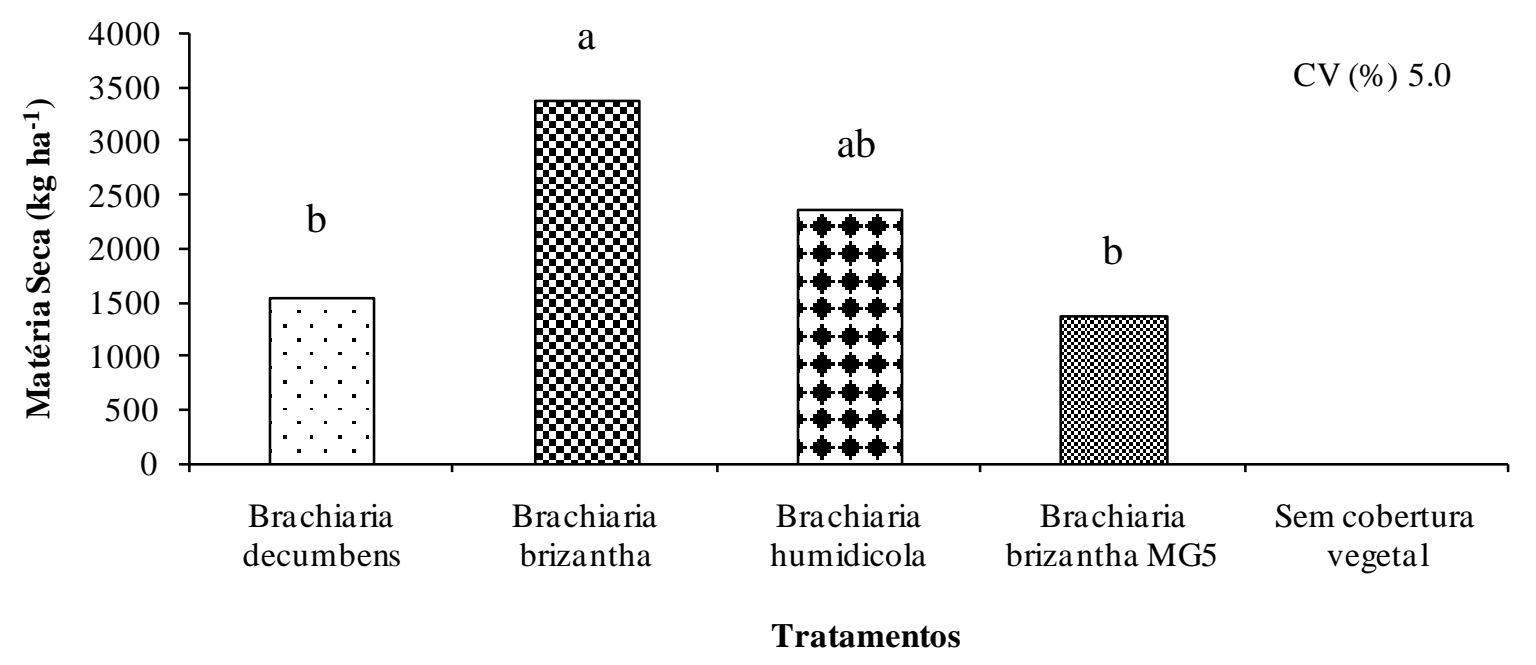

Figura 1. Produção de matéria seca em biomassa de diferentes gramíneas utilizadas como cobertura vegetal em Latossolo no Agreste da Paraíba.

As cultivares da espécie Brachiaria brizantha têm sido recomendadas para plantio nos diversos sistemas de produção de ruminantes em função de sua elevada produção de matéria seca, bom valor nutritivo, boa aceitabilidade e alta capacidade de suporte animal (TEIXEIRA et al., 2003). Os dados do presente estudo comprovam o elevado potencial de produção de matéria seca da cultivar Brachiaria brizantha, que em condições de sequeiro produziu uma quantidade superior a Brachiaria decumbens que é bastante cultivada em pastagens na região Nordeste.

Se comparada a outras espécies forrageiras indicadas para cultivo na região 
Nordeste, a produção de matéria seca da Brachiaria brizantha se sobressai, principalmente em relação ao capim buffel Cenchrus ciliares L., que é uma espécie bastante cultivada em nossa região. Santos et al. (2005), avaliando a caracterização a pasto do capim buffel durante o período seco encontraram valores de produção de massa seca variando de 1215 a $1750 \mathrm{~kg} \mathrm{ha}^{-}$ ${ }^{1}, 19 \%$ a menos que a produção de massa seca da Brachiaria brizantha.

Além do que a espécie pode ser indicada para a utilização em sistema de plantio direto ou mesmo como cobertura do solo, em função da grande quantidade de matéria seca que produz, mesmo em condições de sequeiro. A presença de palhada em superfície promove inúmeros benefícios ao solo como, manutenção dastaxas de infiltração de água, acúmulo de matéria orgânica, aumento da capacidade de armazenamento de água no solo, redução do selamento da camada superficial e aumento na estabilidade de agregados do solo (SANTOS et al., 2017).

Na Figura 2, observa-se os dados de retenção hídrica em matéria seca de diferentes gramíneas utilizadas como cobertura morta em Latossolo no Agreste da Paraíba. Houve variação significativa entre os tratamentos avaliados $(p<0,05)$, com destaque para o T2 - Brachiaria brizantha, com uma capacidade de retenção de retenção hídrica na ordem de $5,57 \mathrm{~g} \mathrm{~g}^{-1}$ na matéria seca. Em seguida destacam-se a Brachiaria brizantha MG5 e a Brachiaria decumbens na retenção de água.

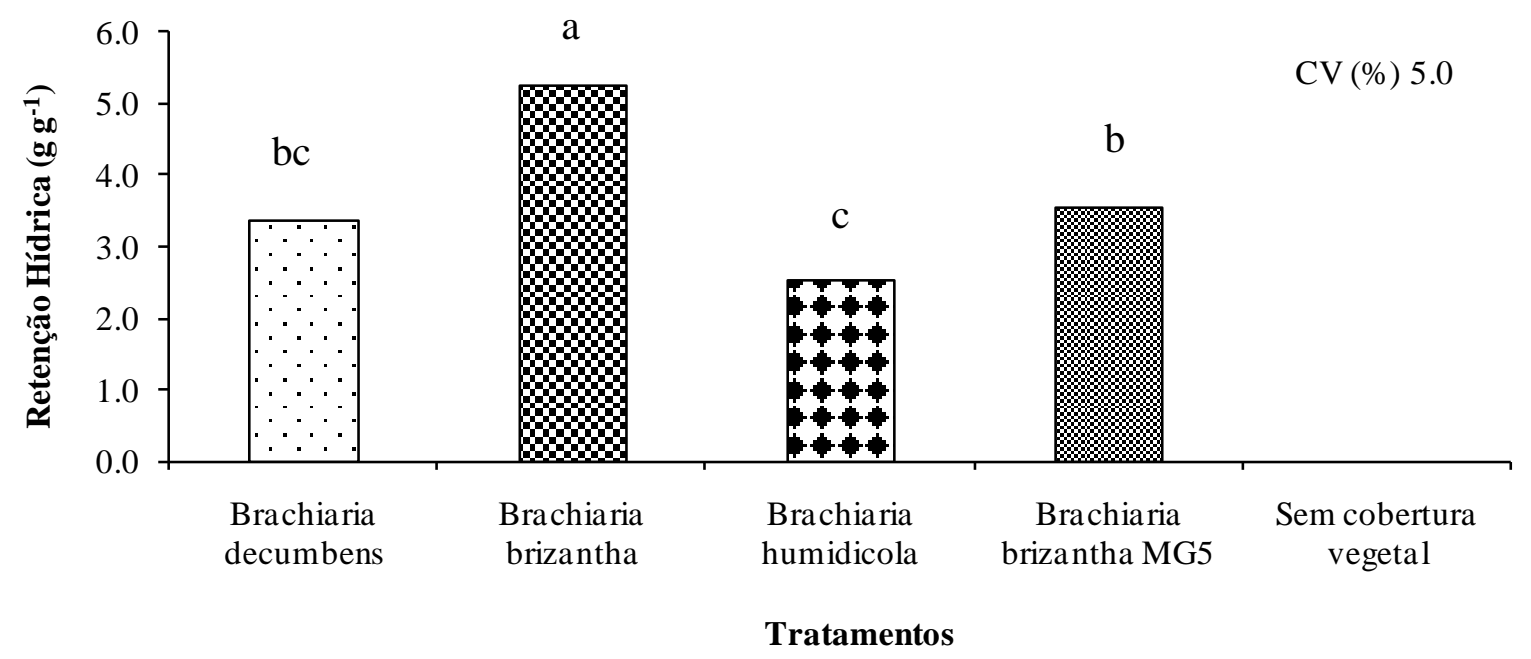

Figura 2. Retenção hídrica em matéria seca de diferentes gramíneas utilizadas como cobertura vegetal em Latossolo no Agreste da Paraíba.

Os dados demostram que há relação direta entre capacidade de retenção hídrica e a produção de matéria secaapenas para a Brachiaria brizantha. A Brachriaria humidicola apresentou a segunda maior produção de matéria seca (Figura 1), contudo sua capacidade de retenção hídrica foi menor que as demais gramímeas avaliadas (Figura 2).

Como a capacidade de retenção hírica tem sido utilizada na escolha da gramínea a ser implantadacomo cobertura de solo (COSTA et al., 2007), verifica-se que a Brachriaria humidicola apresenta elevado potencial para utilização como cobertura do solo em sistemas de produção no Agreste paraibano. Além do que, a elevada produção de matéria seca promove uma cobertura parmanente ao solo, evitando as perdas de água nas épocas mais secas do ano.

Contudo um ponto deve ser observado quanto a escolha da espécie a ser utilizada como cobertura do solo, pois a Brachiaria brizantha apresenta uma taxa de decomposição muito rápida (TORRES 
et al., 2005) e, a elevada capacidade de retenção de água pode favorecer esse processo, já que os microrganismos necessitam de umidade para iniciar o processo de decomposição de resíduos. Segundo Marasca et al. (2011), o tempo necessário para decomposição de $50 \%$ da matéria seca da Brachiaria brizantha é de aproximadamente 71 dias. $\mathrm{Na}$ literatura não existem dados sobre a taxa de decomposição de gramíneas para as condições climáticas do Agreste da Paraíba, principalmente para as espécies avaliadas nesse estudo.

A umidade retida da matéria seca é liberada de forma lenta e gradual no sistema ecológico por meio dos diferentes estágios de decomposição que suas frações apresentam e, dessa maneira, permite a manutenção da umidade na camada superficial do solo (SANTOS et al., 2017). Dessa forma, as duas cultivares que apresentaram maior capacidade de retenção hídrica e, que poderiam de certa forma favorecer a manutenção de umidade do solo na camada superficial, por um período maior de tempo seriam a Brachiaria brizantha e a Brachiaria brizantha MG5.

\section{Estoque de carbono e carbono orgânico total}

Não houve variação estatística significativa ao nível de $(p<0,05)$ para os atributos COT e ESTC entre os tratamentos avaliados, contudo os valores variam de $39,6 \mathrm{~g} \mathrm{~kg}^{-1}$ a $51,9 \mathrm{~g} \mathrm{~kg}^{-1}$ para COT e 47,0 a 64,4 $\mathrm{Mg} \mathrm{ha}^{-1}$ para ESTC (Tabela 3).

Tabela 3. Carbono orgânico total (COT) e estoque de carbono (ESTC) em Latossolo sob diferentes gramíneas utilizadas como cobertura vegetal no Agreste da Paraíba.

\begin{tabular}{ccc}
\hline Tratamentos & COT & ESTC \\
\hline & $-\mathrm{g} \mathrm{kg}^{-1}-$ & $-\mathrm{Mg} \mathrm{ha}^{-1}-$ \\
Brachiaria decumbens & $51,9 \mathrm{a}$ & $64,4 \mathrm{a}$ \\
Brachiaria brizantha & $49,1 \mathrm{a}$ & $59,3 \mathrm{a}$ \\
Brachiaria humidicola & $39,6 \mathrm{a}$ & $47,0 \mathrm{a}$ \\
Brachiaria brizantha MG5 & $40,7 \mathrm{a}$ & $48,4 \mathrm{a}$ \\
Sem cobertura vegetal & $42,2 \mathrm{a}$ & $48,2 \mathrm{a}$ \\
\hline CV \% & 12,5 & 17,1 \\
\hline
\end{tabular}

Médias seguidas pela mesma letra na coluna não diferem entre si pelo teste de Tukey $(p<0,05)$.

O tratamento Brachiaria decumbens foi superior aos demais tratamentos para o estoque de carbono 64,4 $\mathrm{Mgha}^{-1}$, sendo $25,6 \%$ superiorao tratamento sem cobertura vegetal. Esse fato indica que a manutenção permanente de cobertura vegetal em superfície favorece um maior aporte de carbono ao solo. Gazzola et al. (2015), trabalhando com avaliação das frações de matéria orgânica do solo sob pastagem, sistema plantio direto e integração lavoura-pecuária, não verificaram diferença estatística significativa para o carbono orgânico total (COT) entre a as áreas cultivadas com gramíneas e o sistema de plantio direto. Para eles a ausência de ação antrópica favoreve a estabilidade do carbono orgânico no solo, já que a conversão da matéria orgânica do solo em $\mathrm{CO}$ é da mesma magnitude que as perdas de carbono pela mineralização promovida pela atividade microbiana.

A baixa variação nos teores de COT e ESTC entre os tratamentos avaliados pode estar relacionada a ausência de ação antópica nas parcelas cultivadas com as gramíneas, já que o experimento vem sendo mantido ao longo de treze anos e o tratamento sem cobertura vegetal, descoberto desde o ano de 2018, anteriormente apresentava-se coberto com Brachiaria ruziziensis. Esse período de tempo foi suficiente para promover um aumento significativo dos teores de COT nas parcelas com cobertura. 
Verifica-se na Tabela 1, que a elevada produção de matéria seca pela cultivar Brachiaria brizantha exerceu forte influência nos teores de carbono no solo, contudo foi inferior ao tratamento Brachiaria decumbens, que apresentou uma produção de matéria seca na ordem de $1550 \mathrm{~kg} \mathrm{ha}{ }^{-1}$ (Figura 1). As áreas cultivadas com gramíneas, geralmente, apresentam elevada capacidade de acúmulo de MO em função do não revolvimento do solo, aliada a elevada produção de matéria seca em superfície e pela intensa renovação do sistema radicular, que é abundante e permanente (SALTON, 2005).

A elevada produção de biomassa redicular na Brachiaria decumbens em relação as demais cultivares utilizadas, deve ter proporcionado esse aumento significativo no teor de carbono orgânico total e no estoque de carbono no solo avaliado (Tabela 3). Loss et al. (2011) afirmam que o bom desenvolvimento do sistema radicular das gramíneas, principalmente das braquiárias, favorece a formação de agregados e o maior aporte de matéria orgânica, elevando os teores de carbono no solo.

Contudo, observa-se na Tabela 3, que a Brachiaria humidicola apresentou um acúmulo de carbono inferior ao tratamento testemunha, sem cobertura. Possivelmente pela baixa produção de matéria seca em superfície, como verificado na Figura 1, onde a produção foi da ordem de $1371 \mathrm{~kg} \mathrm{ha}^{-1}$. Salienta-se que antes da capina,o tratamento sem cobertura vegetal encontrava-se cultivado com Brachiaria ruziziensis, explicando assim o elevado aporte de carbono em relação à Brachiaria humidicola. Esses dados demonstram que há uma relação direta entre o volume de matéria seca produzida pelas gramíneas e o teor de COT e ESTC no solo. A elevada decomposição do material também pode favorever o baixo aporte de carbono, mesmo as gramíneas apresentando elevada relação $\mathrm{C} / \mathrm{N}$.

Geralmente, quando há conversão de vegetação nativa por áreas de produção agrícola, principalmente em regiões tropicais, verifica-se uma rápida perda de carbono orgânico em decorrência da combinação entre calor e umidade, contribuindo para o acelerado processo de oxidação do carbono orgânico (NEVES et al., 2004).

A manutenção das gramíneas em estádio de conservação favoreceu a manutenção dos teores de carbono em níveis consideráveis, variando de 3 a $5 \%$. Esses valores se assemelham aos encontrados por Rosa et al. (2014), trabalhando com determinação do estoque de carbono em pastagens cultivadas na bacia hidrográfica do rio Paranaíba, para eles uma pastagem bem manejada consegue reter no solo, na camada de 0,00 $0,30 \mathrm{~m}, 15 \%$ mais carbono que uma pastagem degradada.

Quanto a variabilidade dos dados, levando-se em consideração o coeficiente de variação para os atributos avaliados COT e o ESTC, os mesmos apresentaram uma variabilidade média, com $\mathrm{CV}$ variando de $12,5 \%$ para o COT e $17,1 \%$ para o ESTC, conforme estabelecido por Pimentel-Gomes e Garcia (2002). Pode-se afirmar então, que os dados apresentaram certo grau de confiabilidade e que a variação dentro dos tratamentos avaliados ficou dentro da margem de segurança.

$\mathrm{Na}$ Tabela 4, verificam-se os valores de variância para a análise de componentes principais para os atributos COT e ESTC, na camada de $0,00-0,10 \mathrm{~m}$. 
Tabela 4. Valores de variância para análise de componentes principaisem Latossolo sob gramíneas noAgreste da Paraíba.

\begin{tabular}{lcccc}
\hline \multirow{2}{*}{ Componentes da Variância } & \multicolumn{4}{c}{ Componentes principais } \\
\cline { 2 - 5 } & 1 & 2 & 3 & 4 \\
\hline Autovalores & 1,94258 & 0,32233 & 0,03149 & 0,00134 \\
Proporção \% & 84,54 & 14,03 & 1,37 & 0,06 \\
Acumulada \% & 84,54 & 98,57 & 99,94 & 100 \\
\hline
\end{tabular}

\begin{tabular}{ccccc}
\hline \multirow{2}{*}{ Variáveis } & \multicolumn{4}{c}{ Correlação com os componentes principais } \\
\hline CRH & 0,761 & $-0,114$ & $-0,637$ & $-0,033$ \\
MS & 0,570 & $-0,347$ & 0,744 & $-0,027$ \\
COT & 0,206 & 0,716 & 0,152 & $-0,650$ \\
ESTC & 0,230 & 0,595 & 0,128 & 0,759 \\
\hline
\end{tabular}

O coeficiente de variação foi explicado pelos quadrantes 1 e 2 (Tabela 4), com $98,57 \%$ dos dados avaliados. No componente 1 verificou-se a maior proporção e o maior autovalor dos componentes da variância, sendo superior ao componente 2 , onde a proporção foi de 14,03\%.Quanto aos valores de correlação, as variáveis analisadas possuem correlação positiva entre si em relação ao componente principal 1.

Com relação aos valores individuais de correlação por tratamento (Tabela 5), observa-se que o tratamento Brachiaria decumbens foi o único a apresentar uma valor maior que dois $(2,134)$ para o quadrante 1 , possivelmente por ter sobressaído aos demais tratamentos quanto aos teores de COT e ao ESTC acumulados.
O tratamento sem cobertura vegetal apresentou valores individuais negativos nos dois quadrantes $(-0,891$ e $-0,165)$, distanciando dos demais tratamentos avaliados.

Dos valores do coeficiente de variação, 98,54\% foram explicados pelos quadrantes 1 e 2, desta forma, foi possível agrupar entre os tratamentos que a Brachiaria decumbens obteve forte influência do COT e ESTC, e a Brachiaria brizantha e Brachiaria Brizantha MG5, foram fortemente influenciadas pela retenção hídrica e produção de matéria seca. Indicando assim, o potencial dessas cultivares em acumular carbono e reter água no solo através da deposição de matéria senescente. $\mathrm{Na}$ Tabela 5, encontram-se os valores individuais de correlação para a (ACP).

Tabela 5. Valores individuais de correlação para a análise de componentes principais em Latossolo sob gramíneas no Agreste da Paraíba.

\begin{tabular}{ccccc}
\hline \multirow{2}{*}{ Tratamentos } & \multicolumn{4}{c}{ Valores individuais de correlação } \\
\cline { 2 - 5 } & $\mathrm{CP} 1$ & $\mathrm{CP} 2$ & $\mathrm{CP} 3$ & $\mathrm{CP} 4$ \\
\hline Brachiaria decumbens & 0,468 & 0,787 & 0,055 & 0,038 \\
Brachiaria brizantha & 1,740 & $-0,019$ & 0,060 & $-0,045$ \\
Brachiaria humidicola & $-0,258$ & $-0,741$ & 0,168 & 0,028 \\
Brachiaria brizantha MG5 & 0,156 & $-0,258$ & $-0,301$ & 0,011 \\
Sem cobertura vegetal & $-2,1056$ & 0,231 & 0,019 & $-0,032$ \\
\hline
\end{tabular}

Ramos et al. (2019), trabalhando com avaliação de atributos físicos do solo em sistema consorciado e monocultivo de maracujá no estado do Tocantins, verificaram que $93 \%$ do coeficiente de variação foram explicados pelos quadrantes um e dois, observando-se uma tendência de concentração de dados do lado esquerdo do gráfico. Para eles a instalação recente do sistema de consórcio com maracujá (um ano) não proporcionou mudanças nos atributos físicos do solo. No 
caso do presente estudo, o longo período de repousosem manejo das plantas de cobertura proporcionou uma certa estabilidade ao sistema, mantendo os teores de carbono em nível de equilíbrio entre os tratamentos avaliados.

Observa-se na Figura 3, que os componentes 1 e 2 Brachiaria decumbens e Brachiaria brizantha respectivamente, acumularam a maior parte da variância dos dados avaliados. E, referindo-se as médias das variáveis analisadas, observa-se que os tratamentos Brachiaria decumbens e Brachiaria brizantha apresentaram as maiores concentrações de COT e ESTC, enquanto os demais tratamentos, apresentaram um certo distanciameto em relação so eixo principal. De forma geral pode-se observar que as gramíneas favoreceram a manutenção dos teores de carbono no solo, mesmo diante das condições climáticas ao qual o sistema foi implantado.

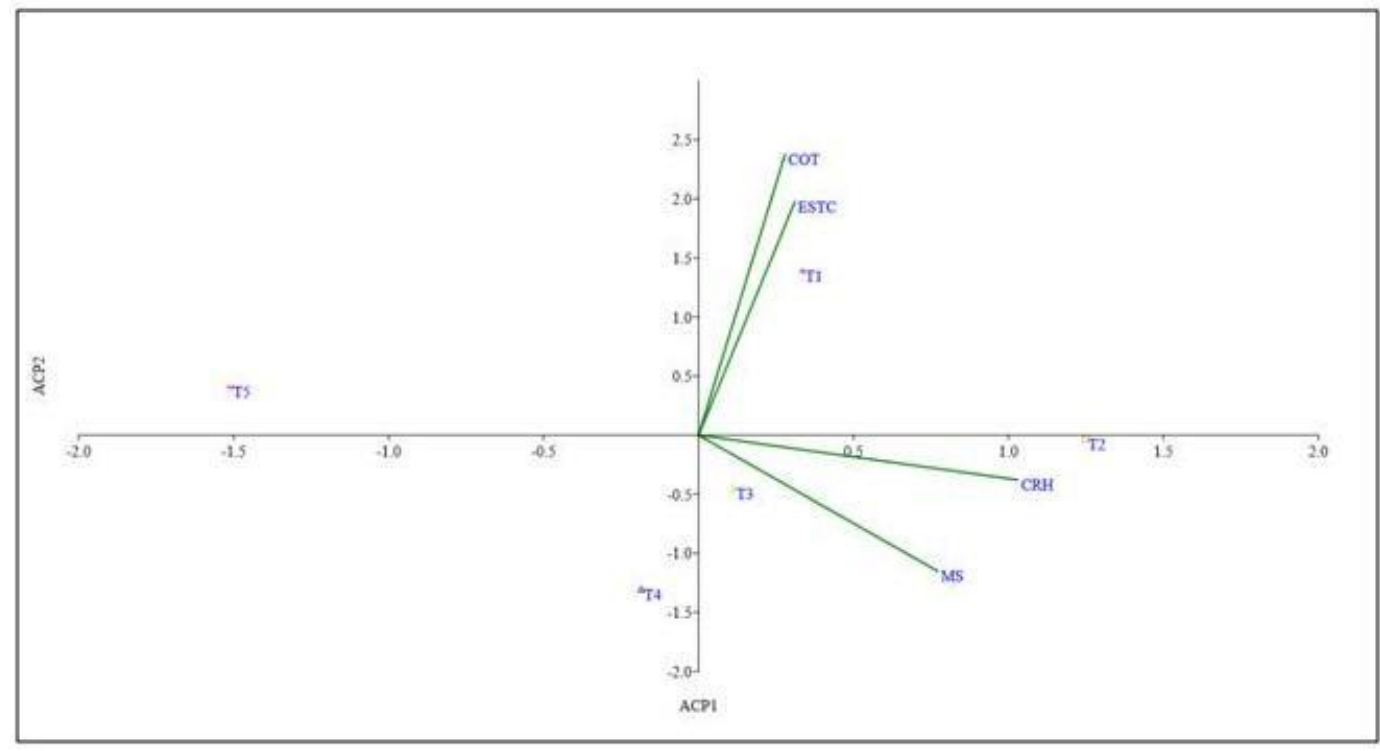

Figura 3. Análise de componentes principais (ACP) para carbono orgânico total (COT), estoque de carbono (ESTC), capacidade de retenção hídrica na matéria seca (CRH) e produção de matéria seca (MS)em Latossolo sob gramíneas no Agreste da Paraíba.

T1- Brachiaria decumbens; T2 - Brachiaria brizantha; T3- Brachiaria humidicola (Rendle) Schweick vr.;T4 - Brachiaria brizantha cv. MG5; - Vitória; T5- Sem cobertura vegetal.

Guareschi et al. (2012), avaliando a deposição de resíduos vegetais, matéria orgânica leve, estoque de carbono, nitrogênio e fósforo remanescente sob diferentes sistemas de manejo no cerrado goiano, chegaram a conclusão que após 15 anos de implantação de sistemas de produção com cobertura do solo, os teores de carbono passam a apresentar uma certa

\section{CONCLUSÕES}

A produção de massa seca e a capacidade de retenção hídrica na massa seca é superior na Brachiaria brizantha.

\section{REFERÊNCIAS}

estabilidade nas camadas superficiais do solo, principalmente em relação aos ambientes conservados. No caso do presente estudo foi possível observar que aos 13 anos de instalação do experimentoa deposição e a ciclagem natural da matéria seca das gramíneas foi eficiente na manutenção e promoção de estabilidade para o COT e ESTC do solo.

O carbono orgânico total e o estoque de carbono permanecem estáveis sob os diferentes sistemas de cobertura do solo após treze anos de plantio das gramíneas. 
ALMEIDA， D. J.; SILVA， I. F.; SILVEIRA, F. P. M.; SANTIAGO, R. D.; COSTA, J. R. C. Poaceae cespitosa e decumbente adubadas com NPK: Efeitos na agregação do solo. Pesquisa Agropecuária Tropical, v. 44, n. 1, p. 50$55,2014$.

BLOW, F. E. Quantity and hydrologic characteristics of litter under upland oak forests in eastern Tennessee. Journal of Forestry, v. 53, n. 3, p. 190-195, 1955. https://dx.doi.org/10.1093/jof/53.3.190

BRAGA, M. B.; MAROUELLI, W. A.; RESENDE, G. M.; MOURA, M. S. B.; COSTA, N. D.; CALGARO, M.; CORREIA, J. S. Coberturas do solo e uso de manta agrotêxtil (TNT) no cultivo do meloeiro. Horticultura Brasileira, v. 35, n. $1, \quad$ p. 147-153, 2017. http://dx.doi.org/10.1590/s0102$\underline{053620170123}$

COSTA, D. M. A.; MELO, H. N. S.; FERREIRA, S. R. Eficiência da cobertura morta na retenção de umidade no solo. Holos, Natal, v. 23, p. 59-69, 2007.

EMPRESA BRASILEIRA DE PESQUISA AGROPECUÁRIA. Sistema brasileiro de classificação do solo - Sibics. 3. ed. Brasília: Embrapa, 2013.

FERNANDES, F. A.; FERNANDES, A. H. B. M. Cálculo dos estoques de carbono do solo sob diferentes condições de manejo. Corumbá: Embrapa Pantanal, 2009. 4 p. (Comunicado Técnico, 69).

FONTES. J. G. G.; FAGUNDES, J. L.; BACKES, A. A.; BARBOSA, L. T.; CERQUEIRA, E. S. A.; SILVA, L. M.; MORAIS, J. A. S.; VIEIRA, J. S. Acúmulo de massa seca em cultivares de Brachiaria brizantha submetida a intensidades de desfolhação. Semina: Ciências Agrárias, v. 36, n. 5, p. 1425-1438, 2014. 2014. http://dx.doi.org/10.5433/1679-

$\underline{0359.2014 \mathrm{v} 35 \mathrm{n} 3 \mathrm{p} 1425}$

GAZZOLA, P. R.; GUARESCHI, R. F.; PERIN, A.; PEREIRA, M. G.; ROSSI, C. Q. Frações da matéria orgânica do solo sob pastagem, sistema plantio direto e integração lavoura-pecuária. Semina. Ciências Agrárias, v. 36, n. 2, p. 693-704, 2015.

GUARESCHI, R. F.; PEREIRA, M. G.; PERIN, A.Deposição de resíduos vegetais, matéria orgânica leve, estoques de Carbono e Nitrogênio e Fósforo remanescente sob diferentes sistemas de manejo no cerrado Goiano. Revista Brasileira de Ciência do Solo, v. 36, n.3, p. 909-920, 2012.

http://www.scielo.br/pdf/pat/v44n1/v44n1a $\underline{02 . p d f}$

LIMA， J. R. S.; SOUZA, E. S.; ANTONINO, A. C. D.; SILVA, I. F.; CORRÊA, M. M.; LIRA, C. A. B. O. Atributos físico-hídricos de um Latossolo Amarelo cultivado e sob mata nativa no brejo paraibano. Revista Brasileira de Ciências Agrárias, v. 9, n. 4, p. 599-605, 2014. http://dx.doi.org/agraria.v9i4a3532

LOSS, A.; PEREIRA, M. G.; GIACOMO, S. G.; PERIN, A.; ANJOS, L. H. C. Agregação, carbono e nitrogênio em agregados do solo sob plantio direto com integração lavoura-pecuária. Pesquisa Agropecuária Brasileira,v. 46, n. 10, p. 1262-1276, 2011.

MARASCA, I. J.; MEDEIROS, L. C.; ARAÚJO, M. J.; PERIN, A.; OLIVEIRA, C. A. A. Teores e acúmulo de nitrogênio, fósforo e potássio e decomposição de biomassa de braquiária em sistema Santa Fé. Enciclopédia Biosfera, v. 7, n. 12, p. 1-9, 2011.

MARTINS, W. B. R.; VALE, R. L; FERREIRA, G. C.; ANDRADE, V. M. S.; DIONÍSIO, L. F. S.; RODRIGUES, R. P.; OLIVEIRA, F. A.; SOUZA, G. M. P. 
Litter fall, litter stock water holding capacity in post-mining forest restoration ecosystems, Eastern Amazon. Revista Brasileira de Ciências Agrárias, v. 13, n. 3, e5546, 2018. http://dx.doi.org/10.5039/agraria.v13i3a55 $\underline{46}$

MIELNICZUK J. Matéria orgânica e sustentabilidade dos sistemas agrícolas. In: SANTOS GA et al. eds. Fundamentos da matéria orgânica do solo - ecossistemas tropicais e subtropicais. 2.ed. Porto Alegre: Metrópole. p. 1- 5. 2008.

NANZER, M. C.; ENSINAS, S. C.; BARBOSA, G. F.; BARRETA, P. G. V.; OLIVEIRA, T. P.; SILVA, J. R. M.; PAULINO, L. A. Estoque de carbono orgânico total e fracionamento granulométrico da matéria orgânica em sistemas de uso do solo no Cerrado. Revista de Ciências Agroveterinárias, v. 18, n. 1, p. 1-10, 2019.

NEVES, C. M. N.; SILVA, M. C. N.; CURI, N.; MACEDO, R. L. G.; TOKURA, A. M. Estoque de carbono em sistemas agrosilvopastotil, pastagem e eucalipto sob cultivo convencional na região Nordeste do estado de Minas Gerais. Ciência e Agrotecnologia,v. 28, n. 5, p. 1038-1046, 2004.

OLIVEIRA, I. A.; LIMA, J. R. S.; SILVA, I. F.; ANTONINO, A. C. D.; GOUVEIA NETO, G. C.; LIRA, C. A. B. O. Balanço de energia em mamona cultivada em condições de sequeiro no Brejo Paraibano. Revista Brasileira de Ciências Agrárias, v. 4, n. 2, p. 185-191, 2009. http://dx.doi.org/10.5039/agraria.v4i2a11

PIMENTEL-GOMES, F. P.; GARCIA, C. $H$. Estatística aplicada a experimentos agronômicos e florestais. Piracicaba, FEALQ, 2002. 309 p.

R DEVELOPMENT CORE TEAM. R: A language and environment for statistical computing. Vienna: $\mathrm{R}$ Foundation for Statistical Computing, 2013.

RAMOS, A. M. R.; AMORIM, B. M. B.; FREIRE, C. T. M.; LIMA, P. L. F. A. Atributos físicos de solo em sistema consorciado e monocultivo do maracujá (Passiflora edulis sims). Brazilian Journal of Byosistems Engineering, v. 13 n. 1, p. 80-87, 2019.

ROSA, R.; SANO, E. E.; ROSENDO, J. S. Estoque de carbono em solos sob pastagens cultivadas na bacia hidrográfica do rio Paranaíba. Sociedade e Natureza, v. 26, n. 2, p. 333-351, 2014.

SALTON, J. C. Matéria orgânica e agregação do solo na rotação lavourapastagem em ambiente tropical.2005. Tese (Doutorado em Ciência do Solo) Programa de Pós-Graduação em Ciência do Solo. Universidade Federal do Rio Grande do Sul, Porto Alegre.

SANTOS, A. F. A.; CARNEIRO, A. C. P.; MARTINEZ, D. T.; CALDEIRA, S. F. Capacidade de retenção hídrica e estoque de serapilheira de eucalipto. Floresta e Ambiente, 24: e20150303, 2017. http://dx.doi.org/10.1590/2179-

8087.030315

SANTOS, G. R. A.; GUIM, A.; SANTOS, M. V. F.; FERREIRA, M. A.; LIRA, M. A.; DUBEUX JÚNIOR, J. C. B.; SILVA, M. J. Caracterização do pasto de capimBuffel diferido e da dieta de bovinos, durante o período seco no Sertão de Pernambuco. Revista Brasileira de Zootecnia, v. 34, n. 2, p. 454-463, 2005.

SILVA, W.; SILVEIRA, A. M. E.; TAVARES, R.; MARTINS, G. S.; LIMA, J. S. Cobertura do solo com material orgânico no desenvolvimento inicial de sorgo forrageiro. Agrarian Academy, v. 5, n. $9, \quad$ p. $122-129,2018$. http://dx.doi.org/10.18677/AgrarianAcade $\underline{\text { my2018a12 }}$ 
SOARES, M. D.; CAMPOS, M. C. C.; CUNHA, J. M.; SOUZA, Z. Z.; OLIVEIRA, A.; AQUINO, R. E.; MANTOVANELLI, B. C.; OLIVEIRA, L. S. Variabilidade espacial do estoque de carbono e atributos físicos do solo em terra preta arqueológica sob pastagem. Revista Ambiente e Água, v. 13, n. 6, p. 1-14, 2018.

TEIXEIRA, G. A.; OLIVEIRA, M. E.; SOUSA JÚNIOR, A.; VERAS, A. S. C.; BATISTA, A. M. V.; ALVES, K. S.; RIBEIRO, V. L.; SILVA, M. J. M. S.; MEDEIROS, G. R.; VASCONCELOS, R. M. J.; ARAÚJO, A. O.; MIRANDA, S. B. Desempenho de ovinos sem raça definida em pastagens dos capins brizantha, tifton85 e Tanzânia. In: REUNIÃO DA SOCIEDADE BRASILEIRA DE ZOOTECNIA, 40., 2003. Santa Maria. Anais... Santa Maria: SBZ, 2003.

TEIXEIRA, P. C.; DONAGEMMA, G. K.; FONTANA, A.; TEIXEIRA, W. G. Manual de métodos de análise de solo. 3. ed. Brasília: Embrapa, 2017.

TORRES, J. L. R.; PEREIRA, M. G.; ANDRIOLI, I.; POLIDORO, J. C.; FABIAN, A. J. Decomposição e liberação de nitrogênio de resíduos culturais de plantas de cobertura em um solo de Cerrado. Revista Brasileira de Ciência do Solo, v. 29, n. 3, p. 609-618, 2005.

VASCONCELOS, R. F. B.; CANTALICE, J. R. C.; OLIVEIRA, V. S.; COSTA, Y. D. J.; CAVALCANTI, D. M. Estabilidade de agregados de um Latossolo Amarelo distrocoeso de tabuleiro costeiro sob diferentes aportes de resíduos orgânicos de cana-de-açúcar. Revista Brasileira de Ciência do Solo, v. 34, p. 309-316, 2010. 